\title{
Evaluation of Recently Developed Regression Equation with Direct Measurement of Low-density Lipoprotein Cholesterol in a Bangladeshi Population
}

\author{
Md. Fazley Rabbi Sha ${ }^{1}$, Abdul Hai Siddique ${ }^{2}$, Muhammad Saiedullah ${ }^{3}$, Md. Aminul Haque Khan ${ }^{4}$ \\ Received: October 9, 2014 Accepted: February 10, 2015 \\ doi: http://dx.doi.org/10.3329/jemc.v5i2.23376
}

\begin{abstract}
Background: Meaningful underestimation of low-density lipoprotein (LDL) cholesterol is an important shortcoming of Friedewald's formula $(F F)$ at higher triglyceride $(T G)$ levels. Recently a regression equation $(R E)$ has been developed using lipid profiles in one setting and validated externally for the calculation of $L D L$ cholesterol. This newly developed RE requires more studies in different settings. Objective: The aim of this study was to evaluate the performance of the regression equation against direct measurement. Materials and Methods: Lipid profiles of 600 subjects attending a tertiary healthcare center were included in this study. Specimens were collected and lipid profiles were measured by standard methods. Sixty two lipid profiles with TG above $400 \mathrm{mg} / \mathrm{dL}$ were excluded. Calculated LDL cholesterol values using FF and RE were compared with measured LDL cholesterol by Pearson's correlation test, Passing \& Bablok regression, accuracy within $\pm 5 \%$ and $\pm 12 \%$ of measured LDL cholesterol and two-tailed paired t test at various TG ranges. Results: The mean value of LDL cholesterol was $148.6 \pm 37.2 \mathrm{mg} / \mathrm{dL}$ for direct measurement, $146.9 \pm 42.4 \mathrm{mg} / \mathrm{dL}$ for $\mathrm{FF}$ and $148.6 \pm 34.7 \mathrm{mg} / \mathrm{dL}$ for RE. The correlation coefficients of calculated LDL cholesterol values with measured LDL cholesterol were 0.949 ( $p<0.001)$ for FF and $0.959(p<0.001)$ for $R E$. Passing \& Bablok regression equation against measured LDL cholesterol was $y=0.897 x+$ 16.2 for $F F$ and $y=1.0842 x-13.1$ for RE. Accuracy within $\pm 5 \%$ of measured $L D L$ cholesterol was $45 \%$ for $F F, 57 \%$ for RE and within $\pm 12 \%$ of measured LDL cholesterol was $84 \%$ for FF, 93\% for RE. When calculated LDL cholesterol was compared with measured $L D L$ cholesterol at different $T G$ ranges, FF significantly underestimated LDL cholesterol at $T G$ concentrations above $200 \mathrm{mg} / \mathrm{dL}$ whereas no significant difference was observed for $R E$. Conclusion: This study reveals that RE equation has similar performance to direct measurement for calculation of LDL cholesterol.
\end{abstract}

Key words: Friedewald's formula; Regression equation (RE) for Bangladeshi

population; Low-density lipoprotein cholesterol

J Enam Med Col 2015; 5(2): 75-79

\section{Intoduction}

Cardiovascular diseases, the leading cause of death worldwide, increase the global health burden. terol is thought to be critically involved in the development of coronary heart disease (CHD) ${ }^{1}$ and it Circulating low-density lipoprotein (LDL) choles- is considered as the primary basis for accurate

1. Research Fellow, Department of Applied Laboratory Sciences, Bangladesh University of Health Sciences, Dhaka, Bangladesh

2. Research Fellow, Department of Cardiovascular Medicine, Tohoku University, Sendai, Japan

3. Assistant Professor, Department of Applied Laboratory Sciences, Bangladesh University of Health Sciences, Dhaka, Bangladesh

4. Professor, Department of Biochemistry, Enam Medical College, Savar, Dhaka, Bangladesh

Correspondence Muhammad Saiedullah, Email: md.saiedullah@gmail.com 
classification in risk categories. ${ }^{2}$ Ultracentrifugation, i.e., b-quantification ${ }^{3}$ is the reference method for the quantitative determination of LDL cholesterol in circulation. Use of this reference method has limitations for routine clinical practice due to technical difficulties. The other recommended methods include homogeneous direct measurement. ${ }^{4,5}$ The direct methods are costly and require expensive automation and are not affordable by most of the laboratories in the developing countries. Because of these limitations clinical laboratories throughout the world use a less expensive and easy approach for the estimation of LDL cholesterol, i.e., Friedewald's formula. ${ }^{6}$ Nearly all laboratories in Bangladesh use this formula for the estimation of LDL cholesterol. In 1972, Friedewald et $\mathrm{al}^{6}$ published the landmark formula by analyzing data of 448 US subjects. This allows rapid, inexpensive and suitable approach for the estimation of LDL cholesterol from three other lipid parameters: serum total cholesterol (TC), serum triglycerides (TG) and serum highdensity lipoprotein (HDL) cholesterol. They developed this formula based on the observation that the ratio of the mass of TG to mass of cholesterol in very low-density lipoprotein cholesterol (VLDL) is apparently constant and it is about 5:1 (in conventional unit). But there are several shortcomings while using this formula - underestimation of LDL cholesterol at higher TG levels ${ }^{7-13}$ and overestimation at low TG levels. ${ }^{14}$ Recently by analyzing lipid profiles from 1.3 million consecutive adult subjects referred for direct measurement of cholesterol subfraction by the Vertical Auto Profile (VAP, density gradient ultracentrifugation or vertical spin density gradient ultracentrifugation) Martin et $\mathrm{al}^{15-17}$ also reported a meaningful underestimation of LDL cholesterol in US adults. These are related to the use of fixed value of TG to VLDL cholesterol. Like the underestimation reported in different population, the underestimation of LDL cholesterol calculated by FF is also common in Bangladeshi population ${ }^{18-25}$ and there is no evidence of systematic overestimation of LDL cholesterol by FF in this population. ${ }^{18-24}$ In 2014 Saiedullah et al published a regression equation by analyzing lipid profiles of 531 adult Bangladeshi subjects which was validated externally using lipid profiles of 952 Bangladeshi subjects using linear regression. ${ }^{24}$ Subsequently it has been evaluated using another set of lipid profiles collected from the setting of external validation group of the previous study ${ }^{25}$ However, it requires external validation using lipid profiles collected from a setting other than equation development and equation validation. In this context, this comparative study was designed to evaluate the performance of the RE against measured LDL cholesterol in this population in a different setting.

\section{Materials and Methods}

This cross-sectional study was conducted in the department of Applied Laboratory Sciences, Bangladesh University of Health Sciences (BUHS) during the period of April to June 2014. Venous blood specimens were collected in tubes without anticoagulant from 600 subjects (after $\sim 12$ hour fast) attending the outpatient department of a tertiary healthcare center for lipid analysis. The specimens were allowed to clot at room temperature, and serum was obtained by centrifugation at $3000 \mathrm{rpm}$ for 15 minutes. Biochemical analyses were done within 12 hours of specimen collection. Serum TG and total cholesterol (TC) were measured by enzymatic endpoint method and high-density lipoprotein (HDL) cholesterol and LDL cholesterol were measured by direct automated method using Dimension RxL Max (Siemens, USA) clinical chemistry analyzer. All kits, calibrators and quality control materials were purchased from Siemens, USA through local distributor. Sixty two lipid profiles with TG concentration above $400 \mathrm{mg} / \mathrm{dL}$ were excluded and 538 lipid profiles with $\mathrm{TG}<400 \mathrm{mg} / \mathrm{dL}$ were included in the study.

LDL cholesterol concentrations were also calculated by Friedewald's formula ${ }^{6}$ and by regression equation. ${ }^{24}$ Calculated LDL cholesterol values were compared with measured LDL cholesterol by Pearson's correlation test, Passing \& Bablok regression, accuracy within $\pm 5 \%$ and $\pm 12 \%$ of measured LDL cholesterol and two-tailed paired $t$ test at various TG ranges. Statistical analyses were performed by MedCalc $\AA$ version 11.4 for Windows. $p$ value $<0.05$ was considered as statistically significant.

\section{Results}

A total of 538 lipid profiles from 538 adult study subjects were included in this study. Among them 
273 were males and 265 were females. The mean age of the study subjects was $48 \pm 13$ years. Lipidemic status of the study subjects is presented in Table I.

Table I: Lipidemic status of the study subjects

\begin{tabular}{|l|r|}
\hline Lipid parameters & Mean \pm SD \\
\hline Total cholesterol (mg/dL) & $226.5 \pm 42.6$ \\
\hline Triglyceride $(\mathrm{mg} / \mathrm{dL})$ & $180.5 \pm 75.7$ \\
\hline HDL cholesterol (mg/dL) & $43.4 \pm 12.4$ \\
\hline Measured LDL cholesterol (mg/dL) & $148.6 \pm 37.2$ \\
\hline Calculated LDL cholesterol by FF (mg/dL) & $146.9 \pm 42.4$ \\
\hline Calculated LDL cholesterol by RE (mg/dL) & $148.6 \pm 34.7$ \\
\hline
\end{tabular}

The mean values of LDL cholesterol was $148.6 \pm$ $37.2 \mathrm{mg} / \mathrm{dL}$ for direct measurement, $146.9 \pm 42.4$ $\mathrm{mg} / \mathrm{dL}$ for $\mathrm{FF}$ and $148.6 \pm 34.7 \mathrm{mg} / \mathrm{dL}$ for RE. Mean value of calculated LDL cholesterol by FF differed from measured value $(\mathrm{p}=0.004)$ whereas mean value of calculated LDL cholesterol by RE did not ( $\mathrm{p}=0.899)$. Comparison of calculated LDL cholesterol with measured LDL cholesterol at different TG ranges is presented in Table II. The correlation coefficients of calculated LDL cholesterol values with measured LDL cholesterol were $0.949(\mathrm{p}<0.001)$ for FF and $0.959(\mathrm{p}<0.001)$ for RE. Passing \& Bablok regression equation against measured LDL cholesterol was $y=0.897 x$ +16.2 for FF (Fig 1A) and $y=1.0842 x-13.1$ for RE (Fig 1B). Accuracy within $\pm 5 \%$ of measured LDL cholesterol was $45 \%$ for $\mathrm{FF}, 57 \%$ for RE and within $\pm 12 \%$ of measured LDL cholesterol was $84 \%$ for FF, $93 \%$ for RE.

Table II: Comparison of calculated LDL cholesterol at various TG ranges with measured LDL cholesterol

\begin{tabular}{|l|l|l|l|l|l|}
\hline TG range & Measured LDL & \multicolumn{2}{|c|}{ FF LDL cholesterol } & \multicolumn{2}{|c|}{ RE LDL cholesterol } \\
& cholesterol & Mean $\pm \mathrm{SD}$ & $p$ values & Mean $\pm \mathrm{SD}$ & $p$ values \\
\hline Up to $100 \mathrm{mg} / \mathrm{dL}(\mathrm{n}=72)$ & $135.6 \pm 33.9$ & $137.6 \pm 38.2$ & 0.145 & $136.1 \pm 31.3$ & 0.620 \\
\hline $101-200 \mathrm{mg} / \mathrm{dL}(\mathrm{n}=279)$ & $154.0 \pm 29.9$ & $155.1 \pm 31.8$ & 0.102 & $153.6 \pm 26.5$ & 0.528 \\
\hline $201-300 \mathrm{mg} / \mathrm{dL}(\mathrm{n}=141)$ & $154.7 \pm 38.7$ & $150.8 \pm 44.7$ & $<0.001$ & $154.8 \pm 37.3$ & 0.912 \\
\hline $301-400 \mathrm{mg} / \mathrm{dL}(\mathrm{n}=46)$ & $117.9 \pm 55.1$ & $100.0 \pm 61.9$ & $<0.001$ & $118.4 \pm 51.8$ & 0.848
\end{tabular}
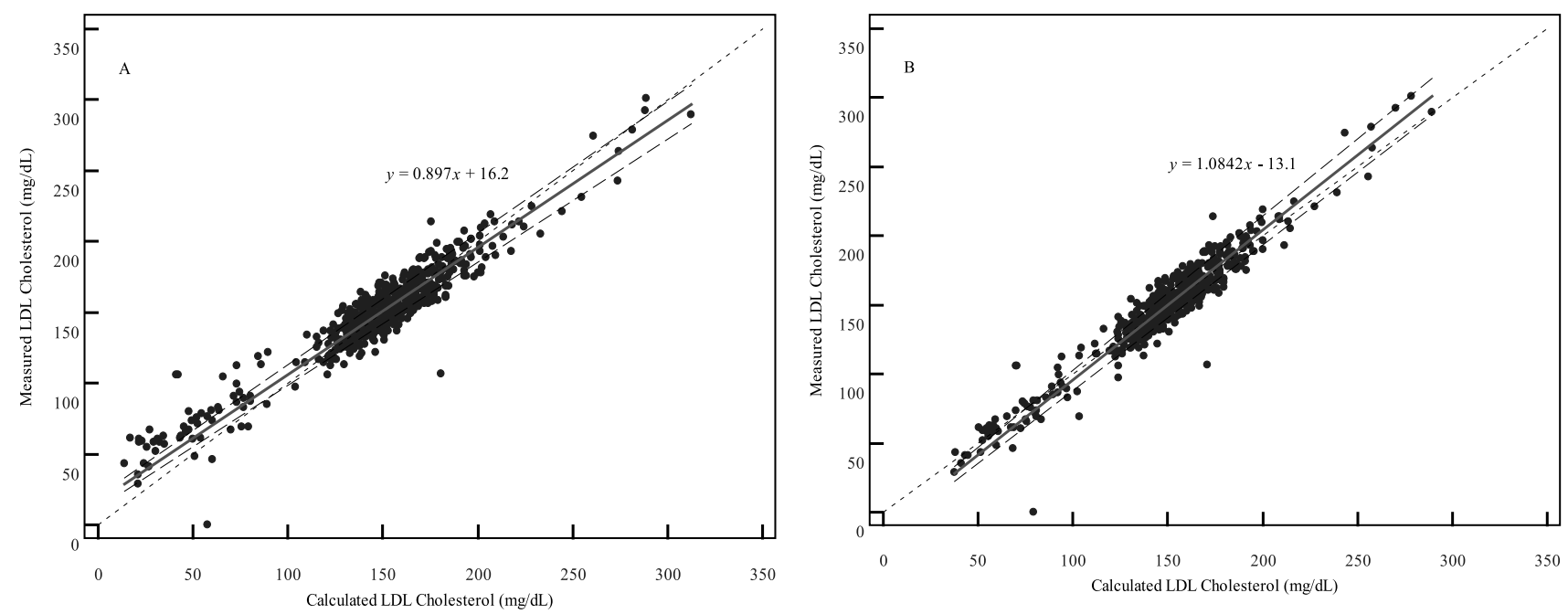

Fig 1. Passing \& Bablok regression equation of calculated LDL cholesterol against measured LDL cholesterol (A for FF and B for RE) 


\section{Discussion}

In this study LDL cholesterol calculated by both FF and RE correlated well with measured LDL cholesterol. The correlation coefficient was stronger for RE compared with FF (0.959 vs 0.949). This is consistent with a previous study done in this population. $^{24}$ Passing \& Bablok regression of calculated LDL cholesterol with measured LDL cholesterol also revealed better agreement of RE with direct measurement compared with that of FF. In this study, though accuracy within $\pm 12 \%$ of measured LDL cholesterol was higher compared to previous study $^{24}$ (84\% vs 57\%) for FF, better accuracy within $\pm 5 \%(57 \%$ vs $45 \%)$ and $\pm 12 \%$ (93\% vs $84 \%)$ of measured LDL cholesterol was observed for RE compared to FF. Differences of mean values of calculated LDL cholesterol using FF with measured LDL cholesterol in the total study subjects were minimal; but it was high and statistically significant at TG concentrations above $200 \mathrm{mg} / \mathrm{dL}$. On the other hand, mean differences were similar and statistically insignificant for RE in the total study subjects as well as at different TG ranges. The underestimation of LDL cholesterol by FF was meaningful and large for Friedewald's formula in US population ${ }^{15,16}$ and it was $>11 \mathrm{mg} / \mathrm{dL}$ in Bangladeshi population. ${ }^{24}$ However, this study revealed that FF underestimated LDL cholesterol by $>17 \mathrm{mg} / \mathrm{dL}$ when TG concentration was above $300 \mathrm{mg} / \mathrm{dL}$. Thus, considering better correlation and accuracy, minimal mean difference of LDL cholesterol by using RE and similar performance to direct measurement, RE can be used in clinical evaluation and in epidemiological studies. However, more studies in different settings are recommended.

Finally, this study reveals that the newly developed regression equation has similar performance to direct measurement for the estimation of LDL cholesterol in this population.

\section{References}

1. Cheng AY, Leiter LA. Implications of recent clinical trials for the National Cholesterol Education Program Adult Treatment Panel III guidelines. Curr Opin Cardiol 2006; 21: 400-404.

2. Expert Panel on Detection, Evaluation, and Treatment of High Blood Cholesterol in Adults. Executive summary of the Third Report of the National Cholesterol Education Program (NCEP) Expert Panel on Detection, Evaluation, and Treatment of High Blood Cholesterol in Adults (Adult Treatment Panel III). J Am Med Assoc 2001; 285: 2486-2497.

3. Bachorick PS, Ross JW. National Cholesterol Education Program recommendations for measurement of lowdensity lipoprotein cholesterol: executive summary. Clin Chem 1995; 41: 1414-1420.

4. Bairaktari ET, Seferiadis KI, Elisaf MS. Evaluation of methods for the measurement of low-density lipoprotein cholesterol. J Cardiovasc Pharmacol Therapeut 2005; 10 : 45-54.

5. Nauck M, Warnick GR, Rifai N. Methods for measurement of LDL-cholesterol: a critical assessment of direct measurement by homogeneous assays versus calculation. Clin Chem 2002; 48: 236-254.

6. Friedewald WT, Levy RI, Fredrickson DS. Estimation of the concentration of low-density lipoprotein cholesterol in plasma, without use of the preparative ultracentrifuge. Clin Chem 1972; 18: 499-502.

7. Lindsey CC, Graham MR, Johnston TP, Kiroff CG, Freshley A. A clinical comparison of calculated versus direct measurement of low-density lipoprotein cholesterol level. Pharmacotherapy 2004; 24: 167-172.

8. Tighe DA, Ockene IS, Reed G, Nicolosi R. Calculated low density lipoprotein cholesterol levels frequently underestimate directly measured low density lipoprotein cholesterol determinations in patients with serum triglyceride levels $\leqslant 4.52 \mathrm{mmol} / \mathrm{l}$ : an analysis comparing the LipiDirect ${ }^{\circledR}$ magnetic LDL assay with the Friedewald calculation. Clin Chim Acta 2006; 365: 236-242.

9. Anwar M, Khan DA, Khan FA. Comparison of Friedewald formula and modified Friedewald formula with direct homogeneous assay for low density lipoprotein cholesterol estimation. J Coll Phys Surg Pakistan 2014; 24: 8-12.

10. Chen Y, Zhang X, Pan B, Jin X, Yao H, Chen B et al. A modified formula for calculating low-density lipoprotein cholesterol values. Lipids Health Dis 2010; 9: 52.

11. de Cordova CM, de Cordova MM. A new accurate, simple formula for LDL-cholesterol estimation based on directly measured blood lipids from a large cohort. Ann Clin Biochem 2013; 50: 13-19.

12. Hattori Y, Suzuki M, Tsushima M, Yoshida M, Tokunaga Y, Wang Y et al. Development of approximate formula for LDL-chol, LDL-apo B and LDL-chol/LDL-apo B as indices of hyperapobetalipoproteinemia and small dense LDL. Atherosclerosis 1998; 138: 289-299.

13. DeLong DM, DeLong ER, Wood PD, Lippel K, Rifkind BM. A comparison of methods for the estimation of 
plasma low- and very low-density lipoprotein cholesterol. The Lipid Research Clinics Prevalence Study. J Am Med Assoc 1986; 256: 2372-2377.

14. Ahmadi SA, Boroumand MA, Gohari-Moghaddam K, Tajik P, Dibaj SM. The impact of low serum triglyceride on LDL-cholesterol estimation. Arch Iran Med 2008; 11: 318-321.

15. Martin SS, Blaha M, Brinton E, Toth P, McEvoy J, Joshi P et al. Clinically meaningful underestimation of LDL-C by Friedewald at levels below $70 \mathrm{mg} / \mathrm{dl}$ : a study of 1.3 million adults. J Am Coll Cardiol 2012; 59: E1693.

16. Martin SS, Blaha MJ, Elshazly MB, Brinton EA, Toth PP, McEvoy JW et al. Friedewald-estimated versus directly measured low-density lipoprotein cholesterol and treatment implications. J Am Coll Cardiol 2013; 62: 732-739.

17. Martin SS, Blaha MJ, Elshazly MB, Toth PP, Kwiterovich PO, Blumenthal RS et al. Comparison of a novel method vs the Friedewald equation for estimating low-density lipoprotein cholesterol levels from the standard lipid profile. J Am Med Assoc 2013; 310: 2061-2068.

18. Kamal AHM, Hossain M, Chowdhury S, Mahmud NU. A comparison of calculated with direct measurement of low density lipoprotein cholesterol level. Journal of Chittagong Medical College Teachers' Association 2009; 20: 19-23.

19. Saiedullah M, Rahman MR, Rahman M, Khan MAH, Begum S. A simple modification of Friedewald's formula to calculate low-density lipoprotein cholesterol up to serum triglyceride concentration of $1000 \mathrm{mg} / \mathrm{dL}$. Bang J Med Biochem 2009; 2: 62-65.
20. Saiedullah M, Sarkar A, Kamaluddin SM, Begum S, Hayat $\mathrm{S}$, Rahman MR et al. Friedewald's formula is applicable up to serum triacylglycerol to total cholesterol ratio of two in Bangladeshi population. Anwer Khan Modern Med Coll J 2011; 2: 21-25.

21. Parvin M, Saiedullah M, Khan MAH, Rahman MR, Islam MS. Validation of the modified Friedewald's formula to calculate low-density lipoprotein cholesterol in Bangladeshi population. J Bangladesh Coll Phys Surg 2012; 30: 141-144.

22. Chowdhury N, Saiedullah M, Khan MAH, Rahman MR. Comparison of modified Friedewald's formula with direct measurement of low-density lipoprotein cholesterol in a Bangladeshi population. Bangladesh Med Res Counc Bull 2013; 39(3): 120-123.

23. Siddique AH, Saiedullah M, Chowdhury N, Khan MAH. Evaluation of performance of the newly developed de Cordova's formula for calculation of low-density lipoprotein cholesterol without use of triglycerides. J Enam Med Col 2014; 4(3): 10-14.

24. Saiedullah M, Chowdhury N, Khan MAH, Hayat S, Begum S, Rahman MR. Comparison of regression equation and Friedewald's formula with direct measurement of low-density lipoprotein cholesterol in Bangladeshi population. J. Sci. Res. 2014; 6: 143-152.

25. Saiedullah M, Chowdhury N, Khan MAH. Evaluation of the novel method and the regression equation for calculation of low-density lipoprotein cholesterol. J Enam Med Col 2015; 5(1): 10-14. 